\title{
Relíquias da Academia Nacional de Medicina III
}

\author{
por \\ Giovanni Guido Cerri' ${ }^{1}$, Cláudio Tadeu Daniel Ribeiro², Paula Padilha Cerqueira ${ }^{3}$, \\ Michele de Almeida Silva \& Carlos Alberto Basilio de Oliveira ${ }^{5}$
}

${ }^{1}$ Acadêmico Titular e Diretor do Museu Inaldo de Lyra Neves-Manta - E-mail: giovanni_cerri@uol.com.br, ${ }^{2}$ Acadêmico Titular e Diretor do Arquivo Sergio d'Avila Aguinága - E-mail: malaria@fiocruz.br, ${ }^{3}$ Arquivista - E-mail: arquivo@anm.org.br, ${ }^{4}$ Bibliotecária - E-mail: biblioteca@anm. org.br $\&{ }^{5}$ Acadêmico Titular e Diretor da Biblioteca Alfredo Nascimento - E-mail: basiliopatologia@br.inter.net da Academia Nacional de Medicina.

\section{Resumo}

Abordando uma temática atual, esta edição do Relíquias da ANM reforça a importância da história para o vislumbre de novos horizontes no campo da profilaxia de doenças transmissíveis. O foco nas vacinas e vacinaçôes revela a importância do acervo do Centro de Memória Médica da ANM para o registro dos fatos referentes às medidas de enfrentamento de epidemias no início do século XX. As charges apresentadas revelam a dificuldade de aceitação pela população de medidas importantes para o enfrentamento da varíola traduzidas pelo episódio da Revolta da Vacina. A obra rara selecionada, o livro de Burggraeve sobre Edward Jenner, o descobridor do procedimento vacinal contra a varíola a partir da doença da vaca, historia o processo de criaçáo da vacina; e a maleta médica evidencia o cotidiano dos médicos do final do século XIX e parte do século XX, quando a prática de vacinação foi iniciada no Brasil. Assim, as peças em análise neste artigo ilustram fatos representativos da época e enriquecem o cenário histórico para entendimento do momento sanitário atual no País e do mundo.

\section{Palavras-chave}

Academia Nacional de Medicina; Epidemias; Vacina; Vacinação; Revolta da Vacina.

\section{Abstract}

Addressing a current theme, this edition of Reliquias da ANM reinforces the importance of history for the glimpse of new horizons in the field of prophylaxis 
of communicable diseases. The focus on vaccines and vaccinations reveals the importance of the collection of the Centro de Memória Médica da ANM for recording facts related to measures to fight epidemics in the early 20th century. The cartoons presented reveal the difficulty of acceptance by the population, translated by the episode of the Vaccine Revolt, of important measures to fight smallpox. The selected Burggraeve's rare book on Edward Jenner, the discoverer of the smallpox vaccine procedure from cow disease, narrates the process of vaccine creation; and the medical bag highlights the physicians' daily life in the late 19th century and part of the 20th century, when the vaccination procedures were initiated in Brazil. Thus, the pieces under analysis in this article illustrate representative facts of the time and enrich the historical scenario for understanding the current sanitary moment in the country and in the world.

\section{Keywords}

Brazilian National Academy of Medicine; Epidemics; Vaccination, Vaccine; Vaccine Revolt.

Vivemos, há mais de um ano, uma grave crise sanitária no Brasil e no mundo pela propagação da pandemia da Covid-19. Nesse período, a desinformação do público leigo tem se agravado por ondas de negacionismo e mesmo de campanhas anticiência e antivacina, que seriam burlescas se trágicas não fossem as suas consequências para a disseminação da doença. Cabe, assim, a associaçóes médicas e sociedades científicas, incluindo as academias, o papel de divulgar permanentemente informaçōes corretas sobre os procedimentos de prevenção da transmissão da doença. Como a reação de parte da populaçáo reproduz em diferentes graus de semelhança aquelas ocorridas por ocasiáo das epidemias de varíola e peste que assolavam a cidade do Rio de Janeiro nos primórdios do século passado, nos pareceu pertinente que o Relíquias da $A N M$ dessa edição salientasse a importância histórica da vacinação a partir do acervo histórico depositado na mais do que secular ANM.

Como apresentado na primeira edição, consta da ata de fundação da nossa Casa a relevância do avanço científico para a instituiçáo, onde se destaca a preocupação da propagaçáo da vacina em meio de diversas epidemias, como febre amarela, peste bubônica, varíola, gripe espanhola, poliomielite, sarampo, H1N1, dentre outras enfrentadas desde o século XIX.

Para ilustrar esta edição do Relíquias da $A N M$ dedicada à vacinação, o Arquivo Sergio d'Avila Aguinága apresenta duas charges nas quais estão representados o ilustre imortal Acadêmico Oswaldo Gonçalves Cruz (18721917) como Diretor Geral de Saúde Pública em meio à Revolta da Vacina (1904).

As reformas urbanas promovidas no início do século XX não eram suficientes para 
modificar o perfil do Rio de Janeiro, cidade conhecida por ser insalubre devido à falta de saneamento básico o que levava à proliferação de vetores e animais hospedeiros de diversas doenças. Mediante a isso, o Presidente Rodrigues Alves nomeia em 1903 como Diretor Geral da Saúde Pública, o então já acadêmico desta Casa, Oswaldo Cruz, que teve papel fundamental na nova política higienista.

Em junho de 1904, o Acad. Oswaldo Cruz apresentou ao Congresso um projeto para reinstaurar a obrigatoriedade da vacinação no País, instituída por proposição do Barão de Pedro Afonso no Brasil Império em 1888, limitando o acesso dos cidadáos nãovacinados para a obtenção de matrículas em escolas, certidóes de casamentos, contratos de trabalho, etc. A charge abaixo ilustra o entendimento popular para com o e a grande insatisfação gerada pelo projeto apresentado.

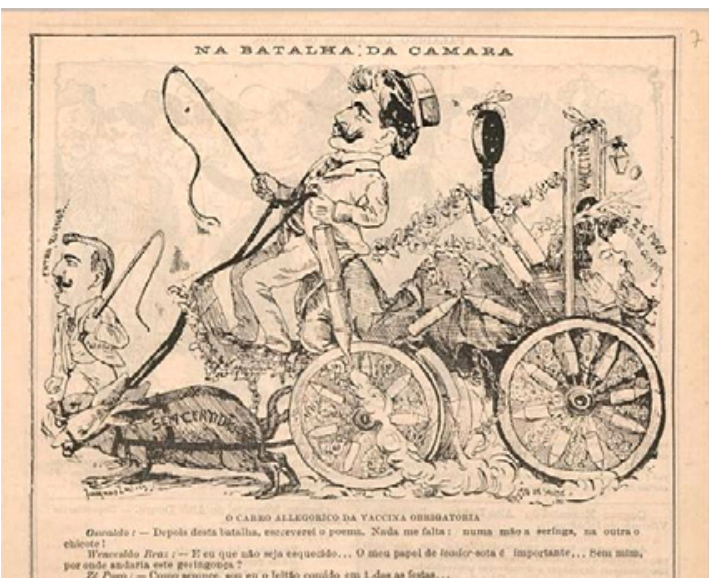

Figura 1: O Malho, $1^{\circ}$ de outubro de 1904.
Com a lei aprovada em outubro do mesmo ano, teve início o processo de vacinação obrigatória na capital do país, o Rio de Janeiro, local no qual a epidemia de varíola assolava a população. A insatisfação com as medidas sanitárias impostas e com a obrigatoriedade da campanha de vacinação levaram à revolta popularconhecidacomo "RevoltadaVacina”. A charge abaixo retrata a proporção da revolta popular nas ruas cariocas:

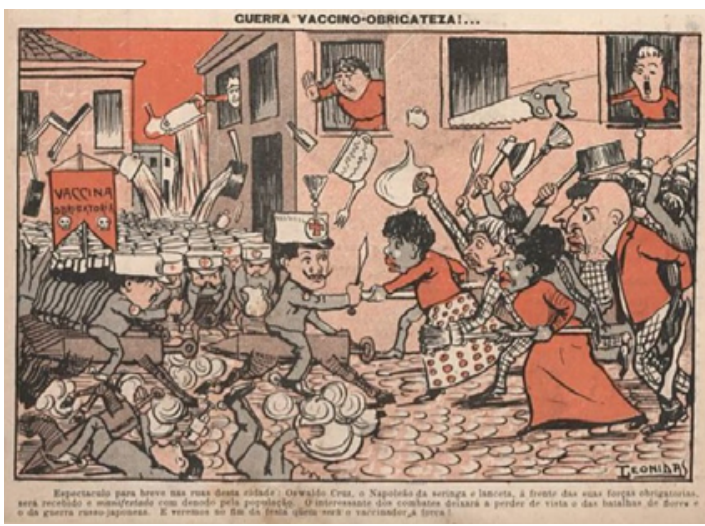

Figura 2: Charge de Leônidas / O Malho, 29 de outubro de 1904.

Os protestos tomaram o espaço público e geraram enfrentamento popular das autoridades sanitárias, policiais e militares. Com o aumento das manifestaçóes, foi decretado estado de sítio no Rio de Janeiro, que reprimiu o movimento com o uso de forças policiais e grande número de pessoas presas e deportadas para o Acre. Entretanto, o governo federal voltou atrás e revogou a obrigatoriedade da vacina.

Mais tarde, em 1908, quando o Rio foi atingido por uma violenta epidemia de varíola, o povo correu para ser vacinado, em um 
episódio avesso ao da Revolta da Vacina. A varíola seria eliminada anos depois com a exigência posterior da vacinação para todas as açóes do estado.

Dentre o vasto acervo de livros raros que pertencem à Biblioteca Alfredo Nascimento está a edição completa da obra Monument à Edw. Jenner ou, Histoire générale de la vaccine: à l'occasion du premier centenaire de son invention (Bruxelas, 1875). Escrito por Adolphe Pierre Burggraeve (1806-1902), o livro conta a história da vacina e de seu inventor, o médico Edward Jenner.

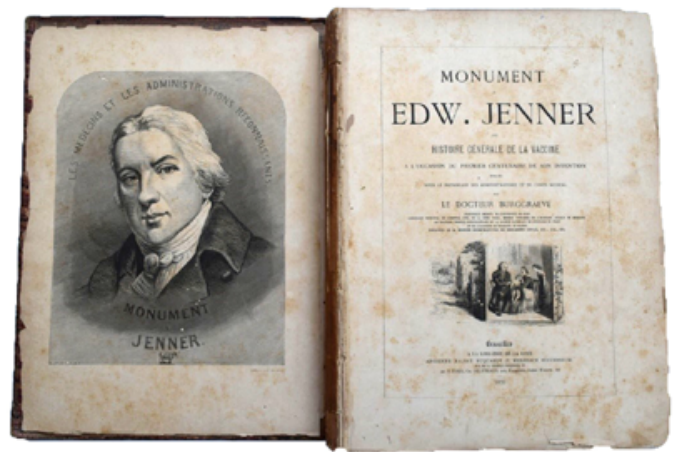

Figura 3: BURGGRAEVE, Adolphe Pierre. Monument à Edw. Jenner ou, Histoire générale de la vaccine: à l'occasion du premier centenaire de son invention. Bruxelles: A la Librairie de la Cour, 1875. xvi, 377 p. [6] f. de lâms. colors. : front. ; $36 \mathrm{~cm}$.

Dr. Jenner (1749-1823) se formou em medicina em Londres, onde foi o responsável pela introdução da imunização contra a varíola e também o primeiro a descrever a arteriosclerose. Em suas observaçóes e experimentos durante uma epidemia de varíola na Inglaterra, usou a metodologia de prevenção através da prática da vacinação, ficando conhecida por jennerização.
A varíola representava um grande flagelo para a humanidade desde os tempos remotos. Sabia-se que os orientais se protegiam contra a doença, com grande risco, mediante inoculação de material pustular humano. Dr. Jenner interessou-se especialmente pelas pessoas acometidas anteriormente pela infecção das vacas ("vacinia"), e que se viam imunes à varíola ou não reagiam à inoculação variólica.

A inspiração para esse método ocorreu ao observar a história das ordenhadeiras que, infectadas por feridas contidas nas tetas das vacas, apresentavam ulceraçóes e reaçóes benignas, mas tornavam-se imunes à varíola humana. Os médicos acreditavam que se tratava apenas de uma antiga lenda popular, todavia, a ideia o intrigou.

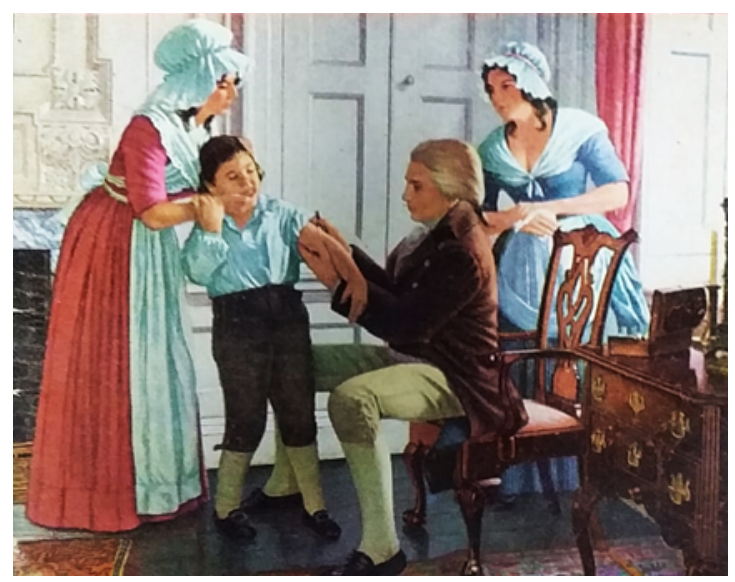

Figura 4. Notas terapêuticas. Parke Davis, v. 39, n. 1, capa, 1962.

Em 1796, Dr. Jenner realizou sua experiência crucial, inoculou no braço do jovem Janes Phipps, na ocasiáo com 8 anos de idade, o material colhido da úlcera da mão 
de uma ordenhadeira com infecção vacinal típica. Entre o sétimo e o nono dias uma reação inflamatória purulenta se manifestou, mas, para se assegurar de seus resultados, Jenner procedeu a uma nova inoculação com material variólico oriundo diretamente de uma pústula de doente.

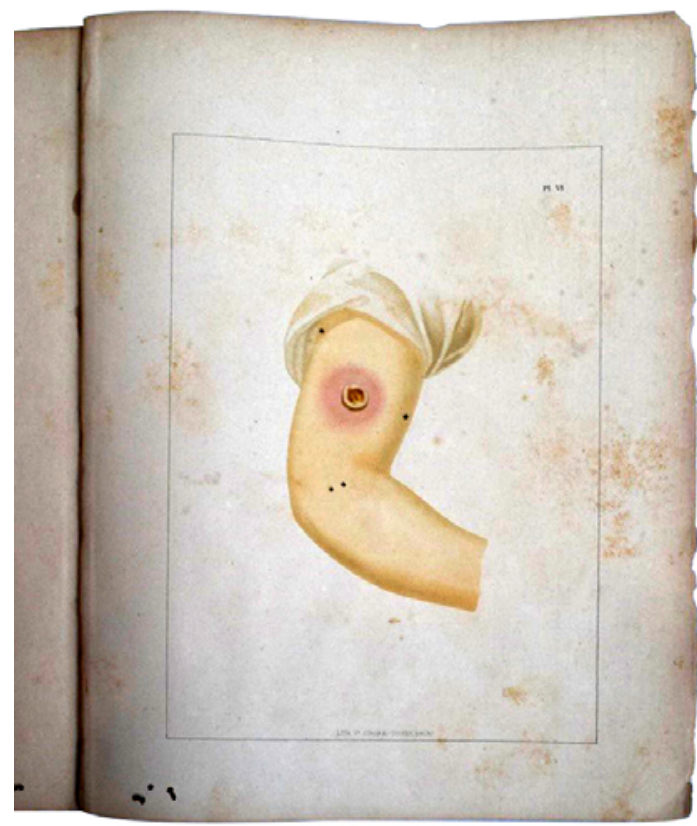

Figura 5: BURGGRAEVE, Adolphe Pierre. Monument à Edw. Jenner ou, Histoire générale de la vaccine: à l'occasion du premier centenaire de son invention. Bruxelles: A la Librairie de la Cour, 1875. xvi, 377 p. [6]f. de lâms. colors. : front.; $36 \mathrm{~cm}$.

Efetivaram-se várias pequenas punções em ambos os braços, sendo o material introduzido cuidadosamente, sem que se manifestasse qualquer indício da doença. Alguns meses mais tarde, repetiu a prova com resultados idênticos. Estava, desta forma, descoberta a vacina contra a varíola, doença que pode ter ceifado centenas de milhóes de vidas, só no século 20 , até ser considerada erradicada do mundo pela Organizaçáo Mundial da Saúde, em 1977. É impossível se estimar com precisão o número de pessoas que morreriam hoje de varíola caso os cientistas não tivessem chegado a uma vacina. Estimativas razoáveis apontam para cerca de 5 milhóes de vidas por ano, o que significa que, de 1980 a 2020, teriam sido salvas cerca de 200 milhôes de vidas.

Os esforços de diversos países ao redor do mundo possibilitaram acesso à vacina. No Brasil, campanhas de vacinaçáo foram promovidas pelo Governo para incentivar a população a se vacinar.

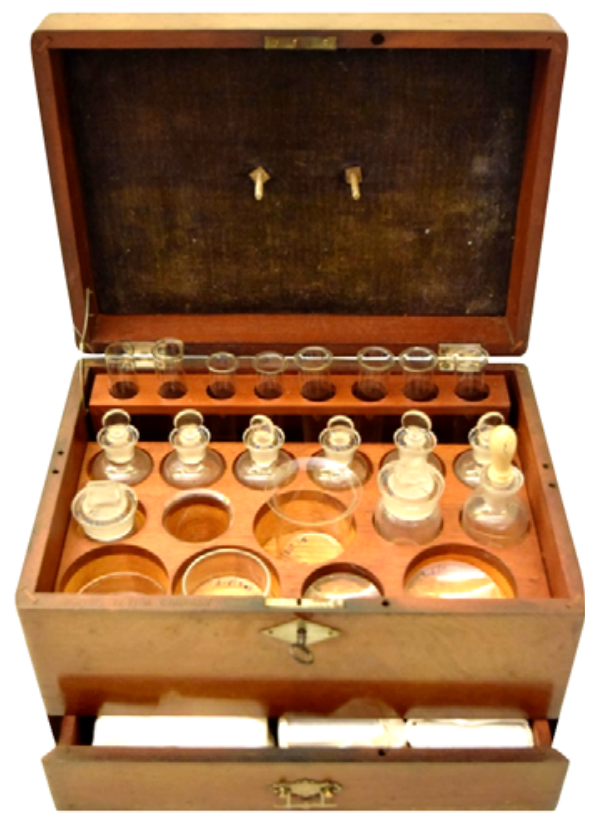

Figura 6. Maleta de vacinação: Pertenceu ao Dr. Flávio da Fonseca, 1938.

No final do século XIX, o Instituto Vacinogênico passou a produzir no país a vacina 
antivariólica com a técnica da jennerização possibilitando uma melhor qualidade de vida para os cidadáos. A atividade de produção desta vacina seria transferida para o Instituto de Manguinhos, em 1922, após a morte do Barão de Pedro Affonso.

Para ilustrar como acontecia o processo de vacinaçáo no Brasil, o Museu Inaldo de Lyra Neves-Manta selecionou para este fascículo a maleta de vacinaçáo, objeto doado pelo Dr. Flávio da Fonseca para a Academia Nacional de Medicina.

A maleta do médico era um utensílio comumente utilizado nos séculos XIX e XX, quando os doutores faziam atendimento nas residências de seus pacientes. Confeccionada em madeira, como representada na figura 6, ela contém geralmente divisórias e uma gaveta. Nos compartimentos possui oito tubos de ensaio, oito frascos de vidro com tampas, um frasco de vidro com pipeta ${ }^{1}$, quatro frascos de vidro sem tampas, três placas pequenas de vidro e, na gaveta, dois pedaços de vela, duas caixas com vacinostilos ${ }^{2}$, dois folhetos de propaganda e um papel timbrado

1 Pipeta Pasteur é um utensílio semelhante a um conta-gotas, geralmente formado por um tubo de vidro de ponta afilada. Serve para efetuar a transferência de pequenas porções de líquidos. Criada pelo químico francês Louis Pasteur, recebe este nome em sua homenagem. Pipeta de Pasteur. Wikipédia: a enciclopédia livre, 10 jan. 2021. Disponível em: https:// pt.wikipedia.org/wiki/Pipeta_de_Pasteur. Acesso em: 22 jun. 2021.

2 Vacinostilo lanceta para vacinar: o vacinostilo é uma espécie de pena metálica não fendida. Dicio, Dicionário Online de Português, 2009-2021. Disponível em: https://www.dicio. com.br/vacinostilo. Acesso em: 22 jun. 2021. da ANM com a inscrição: "Vacinostilos utilizados na primeira metade do século XX, para vacinação antivariólica. Oferecidos pelo Dr. Flávio da Fonseca".
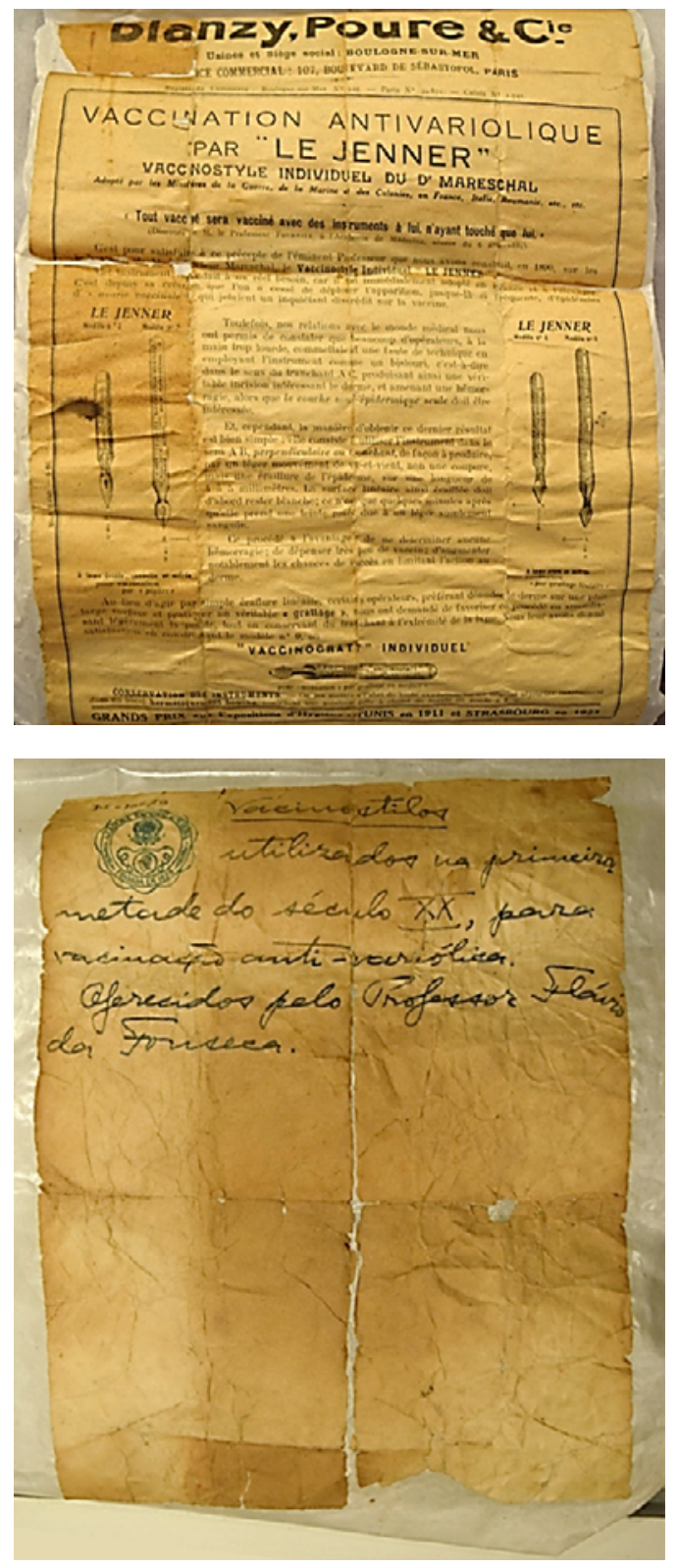

Figura 7 e 8. Folheto de propaganda e papel timbrado da ANM. 
A peça foi objeto de cenário de vários filmes, novelas e minisséries. Em 1998, foi emprestada à produção do filme "Maná, o Imperador e o Rei". A Rede Globo solicitou o empréstimo para à produção da novela "Força de um desejo" em 1999, fez parte do filme "Duas vezes com Helena" em 2000 e também compôs à produção da minissérie "Os Maias" da Rede Globo em 2001. A peça foi exibida na exposição "A Ciência e a Saúde Pública" organizada pela Fundação Oswaldo Cruz em 2000.

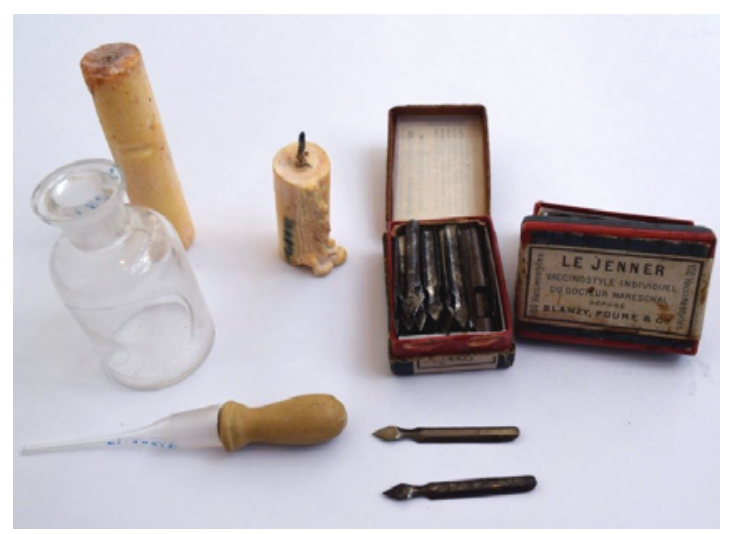

Figura 9: Frasco de vidro com pipeta, pedaços de vela e caixas com vacinostilos.

\section{Conclusão}

Esta edição do Relíquias da ANM é dedicada à história da vacinação a partir de três peças oriundas dos Arquivo, Biblioteca e Museu do Centro da Memória Médica. As charges trazem, a partir do humor, uma reflexão histórica acerca do movimento Revolta da Vacina e a luta do Governo para instruir a população sobre a vacinação. A obra rara conta a história da vacina e de seu inventor, o médico Edward Jenner, e a maleta médica ilustra a sucessão dos dias dos médicos que visitavam os seus pacientes, inclusive para o procedimento vacinal, em seus domicílios, ao fim do século XIX e durante boa parte do século XX. Trata-se de peças históricas que apesar do tempo, voltam à moda enriquecendo o cenário atual sobre questôes médicas, que nunca deixaram de fazer parte do cotidiano ilustrativo de cada época.

\section{REFERÊNCIAS BIBLIOGRÁFICAS}

BBC NEWS BRASIL. Vacinas evitam 4 mortes por minuto e poupam $\mathrm{R} \$$ 250 milhōes por dia. Disponível em HTTPS://WwW.BBC.COM/PORTUGUESE/ INTERNACIONAL-5402964I. Acesso em: 22 jun. 2021.

BURGGRAEVE, Adolphe Pierre.

Monument à Edw. Jenner ou, Histoire générale de la vaccine: à l'occasion du premier centenaire de son invention.

Bruxelles: A la Librairie de la Cour, 1875. xvi, 377 p. [6] f. de lâms. colors.: front.; $36 \mathrm{~cm}$.

Charge "Na batalha da câmara; O carro alegórico da vacina obrigatória". Jornal $\mathrm{O}$ Malho, $1^{\circ}$ de outubro de 1904.

DAVIS, Parke. Notas terapêuticas. v. 39, n. 1, capa, 1962. 
FUNDAÇÃO OSWALDO CRUZ. Museu da Vida. Vacina antivariólica. 29 jun. 2015. Disponível em: HTTP://Www.MUSEUDAVIDA. FIOCRUZ.BR/INDEX.PHP/MUSEOLOGICO/ OBJETO-EM-FOCO/ACERVO-MUSEOLOGICOVACINA-ANTI-VARIOLICA. Acesso em: 22 jun. 2021.

LEONIDAS, O Malho, 29 out. 1904.

\section{Agradecimentos}

Os autores são gratos à Doutora Ana Luce Girão Soares de Lima (Pesquisadora da Casa de Oswaldo Cruz, Fiocruz, Rio de janeiro) pela revisão crítica do manuscrito. 